\section{Drought Resistance in Centipedegrass Cultivars}

\author{
James E. Hook \\ Department of Crop and Soil Sciences, University of Georgia, P.O. Box 748, \\ Tifton, GA 31793
}

Wayne W. Hanna

U.S. Department of Agriculture-Agricultural Research Service, Forage and Turf Research Unit, P.O. Box 748, Tifton, GA 31793

Additional index words. Eremochloa ophiuroides, turfgrass, irrigation, dehydration avoidance

\begin{abstract}
In our study, we sought to determine if an experimental cultivar of centipedegrass ['TC178'; Eremochloa ophiuroides (Munro) Hack.] had superior turf characteristics under extended droughts. Common centipedegrass $(\mathrm{CC})$, vegetatively propagated ' $\mathrm{TC178}$ ' (VG178), and seed-propagated $\left(\mathrm{F}_{3}\right)$ ' $\mathrm{TC178}$ ' (SD178) were evaluated in a 2-year controlled watering study that compared turf characteristics and drought resistance. The grasses were established under an automated rainfall shelter and were subjected to three drought regimes: watered twice per week (no stress), 2 to 3 weeks between watering (moderate), and 4 to 6 weeks between watering (severe). Turf characteristics (visual rating and clipping biomass) were measured weekly and soil water content profiles were measured daily. Visual ratings among cultivars were similar for no-stress conditions, but visual ratings of SD178 and VG178 were $18 \%$ higher than for CC for moderate stress and $28 \%$ higher for severe stress. At the end of moderate stress periods, clipping biomass of VG178 was $24 \%$ greater than for $\mathrm{CC}$, but by the end of the severe stress periods, biomass from VG178 was 22\% lower than for CC. Available soil water content profiles indicated that the three cultivars extracted soil water at the same rate. Visual ratings and growth decline with survival under severe stress showed that VG178 and SD178 had significantly better drought resistance than $\mathrm{CC}$. ' $\mathrm{TC178}$ ' provides a superior appearance turf that will stand up to the droughts common in its adapted region.
\end{abstract}

Centipedegrass is a popular turfgrass throughout much of the southeastern United States. Managed for low-maintenance, centipedegrass is short statured and slow growing and does not require frequent mowing. It tolerates moderately acidic, low-fertility soils; requires little $\mathrm{N}$; and is relatively nonsusceptible to diseases and insects. It also has excellent heat and shade tolerance, although little cold tolerance (Beard, 1982; Johnston and Dickens, 1976). For improved appearance, centipedegrass requires more mowing in late, compared to early, summer and fall to remove seed heads, additional $\mathrm{N}$ or $\mathrm{Fe}$ to darken its normally light green pigmentation, and moderate irrigation to maintain a dense sod and to promote regrowth after traffic damage (Beard, 1982; Carrow and Johnson, 1989, 1990; Johnson, 1990). Centipedegrass water use is considered low (Beard, 1985), and in minilysimeter tests, daily evapotranspiration (ET) of well-watered centipedegrass was among the lowest of nine warm-season lawn grasses compared by Kim and Beard (1988). Centi-

\footnotetext{
Received for publication 6 Dec. 1993. Accepted for publication 3 Aug. 1994. Research conducted at the Coastal Plain Expt. Station, Tifton, Ga., and supported by the O.J. Noer Rese Foundation, Milwaukee, and state and Hatch funds allocated to the Georgia Agricultural Expt. Station. The cost of publishing this paper was defrayed in part by the payment of page charges. Under postal regulations, this paper therefore must be hereby marked advertisement solely to indicate this fact.
}

pedegrass survives and regrows after extended drought, but stand and appearance are poor (Hook et al., 1992).

Despite widespread use in the southeastern United States, relatively little genetic improvement has been made in centipedegrass because of its little genetic variation (Dickens et al., 1981). Lack of genetic variation limits potential for developing improved turf cultivars. An $\mathrm{F}_{2}$ population of 500 plants was produced by open pollination between a green-stemmed selection in Tifton, Ga., and common centipedegrass (CC). From this population, five plants that remained green during an extended drought were vegetatively propagated and maintained in nursery plots. The grass was mowed three times per week at $38 \mathrm{~mm}$, but plots were not irrigated. One of those five $\mathrm{F}_{2} \mathrm{~s}$ ('TC178') did not wilt and showed superior turf characteristics during severe droughts in the mid-1980s. In the same nursery, CC wilted severely.

Preliminary investigations of stomatal characteristics, rooting patterns in the nursery, and water use in the greenhouse (unpublished data) did not provide simple explanations for the superior drought resistance that was displayed by 'TC178' in the nursery. We conducted this study to determine whether 'TC178' is superior to $\mathrm{CC}$ and consistent in its response to extended drought. Additionally, we sought evidence for the mechanism of drought resistance that could explain the superior traits of 'TC178'.
Thirty-six, $2 \times 2-\mathrm{m}$ grass plots with $0.3-\mathrm{m}$ bare-soil borders were established under an automated rainfall shelter (Maw and Stansell, 1986) at the Coastal Plain Expt. Station in Tifton, Ga. The Tifton soil (fine, loamy, thermic Plinthic Kandiudult) had a loamy sand surface over a sandy clay loam subsoil $(84.5 \%$, $9.1 \%, 6.4 \%$ over $68.6 \%, 9.7 \%, 22.1 \%$ sand, silt, clay, respectively). A root-restrictive, platy-plinthite layer occurred at 1000 to 1100 $\mathrm{mm}$. Plots were arranged in a randomized complete-block design with four replications. The treatment design was a $3 \times 3$ factorial. Factors were three centipedegrass cultivars and three drought stress regimes.

Cultivars were vegetatively propagated plants of experimental cultivar TC178 (VG178), vegetatively propagated seed progeny of 'TC178' (SD178), and vegetatively propagated CC. SD178 was produced from selfed seed from an $\mathrm{F}_{3}$ isolation block of 'TC178'. Centipedegrass cultivars were sprigged on $30-\mathrm{cm}$ centers within each plot in June 1988 and that year managed to establish a uniformly complete sod.

Drought stress regimes were created by watering every Tuesday and Friday (no stress), every 14 days (moderate stress), or every 28 days (severe stress). After the first 28-day cycle was complete with relatively few severe stress days, drought cycles were lengthened. The moderate and severe drought treatments were extended to 21 and 42 days, respectively. Drought cycles were repeated four times, two back-to-back cycles in 1989 and another two in 1990.

The amount of irrigation for the no-stress treatment was calculated to apply $100 \%$ of the average pan evaporation each week. For the moderate stress treatment, irrigation quantity was calculated as the amount to refill the upper $70 \mathrm{~cm}$ of soil (i.e., $67 \mathrm{~mm}$ ), but this amount was increased in the third and fourth cycles to add an excess amount to refill and drain. At the end of a 28-day, dry-down cycle (two cycles for the moderate stress treatment), all plots received enough water to thoroughly rewet the soil profile to $120 \mathrm{~cm}$. Individual plot irrigators consisted of 13 solid-cone spray nozzles (model TeeJet SX3; Spraying Systems Co., Wheaton, Ill.) mounted in a shielded frame that added water to $1.7 \times 1.7-\mathrm{m}$ areas at 68 $\mathrm{mm} \cdot \mathrm{h}^{-1}$. A summary of the meteorological observations during the four drought cycles has been published previously (Hook et al., 1992).

Soil water content (SWC) was determined from daily readings of soil water sensors (Watermark; Irrometer Co., Riverside, Calif.). These sensors were positioned near the center of the depth increments ( 0 to 70,70 to 150,150 to 300,300 to 450 , and 450 to $700 \mathrm{~mm}$ ) in a hole bored at the center of each plot during the 1988 grass establishment year. In Fall 1989, a sixth sensor was added at $800 \mathrm{~mm}$ after 1989 observations showed that soil water was thoroughly extracted from the upper $700 \mathrm{~mm}$. We computed SWC for each depth from the resistance readings of the sensors using water re- 
tention curves previously reported for this soil (Hook, 1985). SWC was expressed as available soil water, where the upper and lower limits represent soil water at the upper and lower limits of the sensors $(-10$ and $-160 \mathrm{kPa}$, respectively). These limits correspond to 0.175 and $0.070,0.200$ and 0.125 , and 0.250 and $0.140 \mathrm{~m}^{3} \cdot \mathrm{m}^{-3}$ for the upper and lower limits of the depth increments ( 0 to 300,300 to 450 , and 450 to $900 \mathrm{~mm}$, respectively). The total available SWC calculated from these limits was 70 $\mathrm{mm}$ for the $700-\mathrm{mm}$ profile (Hook et al., 1992). At $-1500 \mathrm{kPa}, \mathrm{SWC}$ was $0.065,0.120$, and $0.130 \mathrm{~m}^{3} \cdot \mathrm{m}^{-3}$ for the same depths, and thus, the total available SWC represents $94 \%$ of upper limit to $-1500 \mathrm{kPa}$ water content.

The slopes of the dry-down curves were calculated for each replication from the daily total available SWC from observations made on day 7 through day 13 following the last watering. During this period, the grass recovered from the previous drought cycle, and total available SWC was high enough that ET was not limiting. These slopes during dry-down represent water withdrawal rates or ET during these 7-day periods. Similarly, slopes of drydown curves were compared among cultivars for each layer to determine if the exploitation patterns differed, suggesting a different root structure.

Every Friday, before scheduled watering, clipping biomass was measured on $1.2 \times 1.2 \mathrm{~m}$ of each plot by using a rotary mower with a bagging attachment. Mowing height was 40 $\mathrm{mm}$. Clippings were dried overnight at $65 \mathrm{C}$ and then weighed.

Every Tuesday, before scheduled watering, visual ratings were made for each plot using a 1 to 9 scale, where $1=$ no living grass and $9=$ a dense, uniform, bright-green, nonstressed turf. Plot ratings were lowered for leaf curling, thinning, dead patches, and nonuniformity.

Analyses of daily, weekly, or seasonal data were made within sampling dates using a fixed effect model of cultivar, stress, and cultivar by stress in an analysis of variance (ANOVA) (SAS Institute, 1982). Linear slopes of the SWC vs. time observations were calculated for each replication using a least squares fit. The hypothesis finding no difference in these slopes among cultivars was tested using the same fixed effect model in general linear model (GLM) (SAS Institute, 1982).

\section{Results}

Soil water extraction. According to the test for difference of the SWC slopes during the dry-down periods, there was no difference in rates at which the three cultivars extracted soil water from the 700-mm profile. Available SWC in the topsoil (300 mm) fell below $20 \%$ on $15,12,12$, and 10 days after irrigation for the severe stress treatments in cycles 1 to 4 , respectively. For moderate stress, which had two dry-down periods per cycle, available SWC in the topsoil fell below $20 \%$ on 15,9 , $12,14,12,12,10$, and 12 days after irrigation for the eight dry-down periods, respectively. There were no differences among cultivars in the length of time required to remove this much available SWC from the topsoil and no difference in the patterns of successive exploitation of deeper layers.

Total available SWC in the profile for severe (Fig. 1) and moderate stress (Fig. 2) treatments declined rapidly during the 7- to 10-day period that began 5 to 7 days after the last watering. The slopes of the SWC curves (i.e., the water extraction rates for the 7 th through 13 th day after watering) averaged 4.0, $12.0,6.8$, and $6.5 \mathrm{~mm} \cdot \mathrm{day}^{-1}$ for the first drydown of cycles 1 to 4, respectively. ANOVA (GLM) of the slopes showed that there was no difference among cultivars or between the moderate and severe stress treatments and no

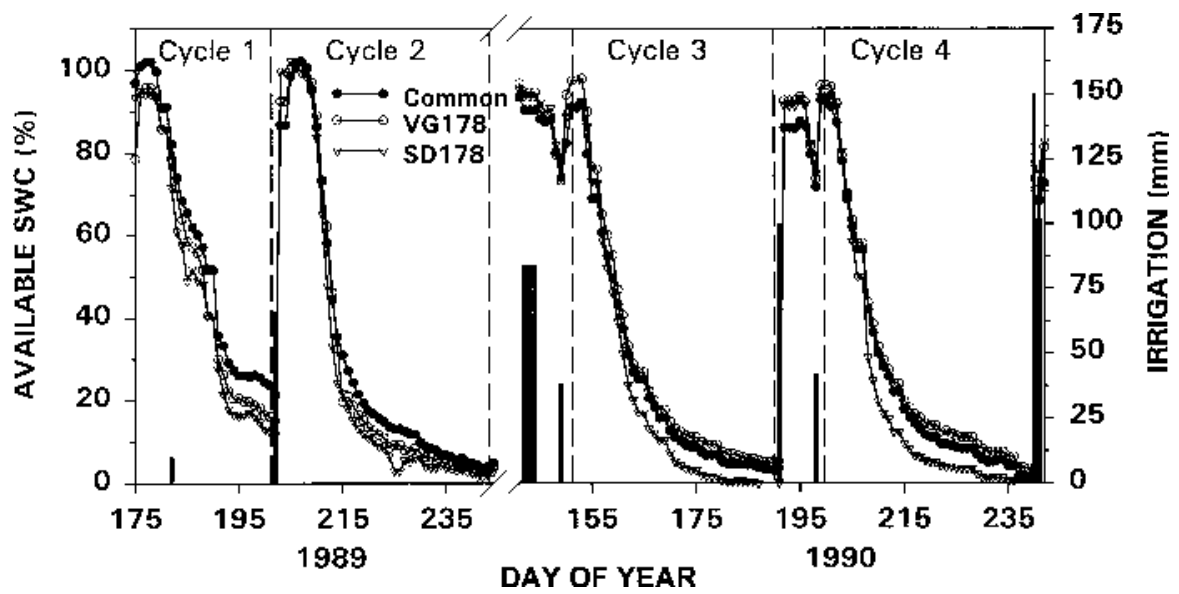

Fig. 1. Daily averages for the total available soil water content (SWC) of the 0- to 700-mm-depth increment for common, VG178, and SD178 centipedegrass turf and irrigation applied (bars) during four cycles of the severe drought stress treatment.

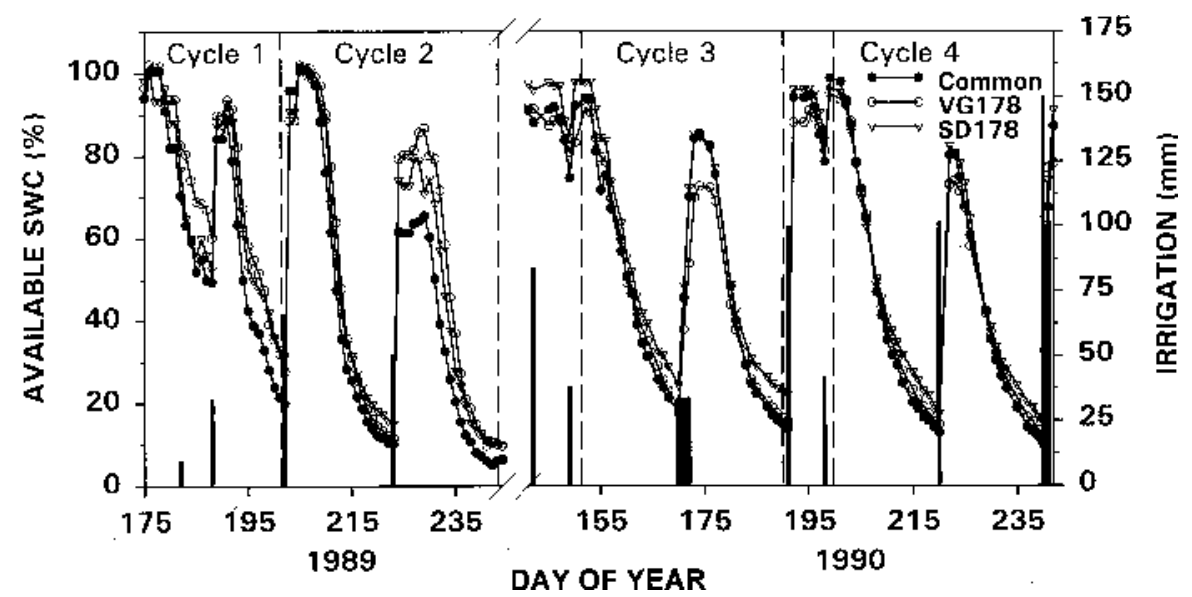

Fig. 2. Daily averages for the total available soil water content (SWC) of the 0 - to 700 -mm-depth increment for common, VG178, and SD178 centipedegrass turf and irrigation applied (bars) during four cycles of the moderate drought stress treatment.

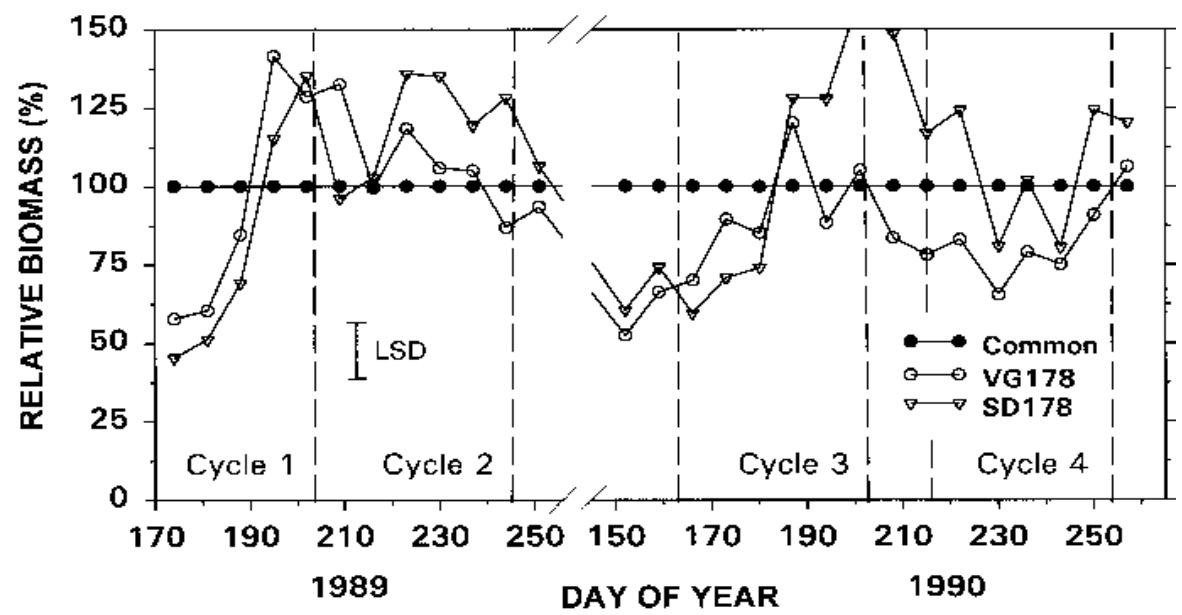

Fig. 3. Relative clipping biomass of common (100\%), VG178, and SD178 centipedegrass for the no-stress treatment. Vertical bar is SE of the mean. 
interactions. These results agree with those of an earlier greenhouse pot study that showed that these cultivars use water at the same rate when water is not limiting (Hook, unpublished data).

Growth differences. When well watered, $\mathrm{CC}$ produced more clippings, expressed as relative biomass, between Julian day 145 and 185 , during late spring and early summer, than VG178 or SD178 (Fig. 3). After $\approx 4$ July 1989 (day 185), the nonstressed VG178 and SD178 surpassed clipping production of CC. Average clipping biomass produced by the three grasses under no stress was $11,17,7$, and $15 \mathrm{~g} \cdot \mathrm{m}^{-2} \cdot$ week $^{-1}$ in cycles 1 through 4 , respectively. biomass production also was affected by stress. Comparison of relative clipping biomass produced during the last 2 weeks of the cycles, when treatment effects had been imposed long enough to affect growth, showed that VG178 grew faster than $\mathrm{CC}$ when well watered, but grew slower than CC under severe stress (Table

Table 1. Relative clipping biomass and visual rating for observations made during the last 2 weeks of four drought cycles for three centipedegrass cultivars and three stress treatments.

\begin{tabular}{lccl}
\hline \hline & \multicolumn{3}{c}{ Watering regimes $^{\mathrm{z}}$} \\
\cline { 2 - 4 } Cultivar & No stress & Moderate & Severe \\
\hline \multicolumn{4}{c}{ Relative biomass $^{y}$} \\
Common & $100.0 \mathrm{~b}^{\mathrm{x}}$ & $69.7 \mathrm{~cd}$ & $60.1 \mathrm{de}$ \\
SD 178 & $102.7 \mathrm{~b}$ & $77.6 \mathrm{c}$ & $49.8 \mathrm{ef}$ \\
VG 178 & $123.9 \mathrm{a}$ & $79.5 \mathrm{c}$ & $47.0 \mathrm{f}$ \\
\multicolumn{4}{c}{ Visual rating } \\
Common & $8.4 \mathrm{a}$ & $5.4 \mathrm{c}$ & $3.4 \mathrm{e}$ \\
SD 178 & $8.1 \mathrm{a}$ & $6.2 \mathrm{~b}$ & $4.6 \mathrm{~d}$ \\
VG 178 & $8.5 \mathrm{a}$ & $6.5 \mathrm{~b}$ & $4.1 \mathrm{~d}$ \\
\hline
\end{tabular}

${ }^{2}$ Drought regimes: no stress, watered twice per week; moderate, 2 or 3 weeks between watering; severe, 4 or 6 weeks between watering.

${ }^{\mathrm{y}}$ Values are relative to nonstressed common centipedegrass $=100$.

${ }^{x}$ Within observed variables, interaction means separation at $P \leq 0.05$; least significant difference $=$ $12.4 \%$ for relative biomass, 0.7 for visual rating. ${ }^{\text {w}}$ Visually rated on a scale from 1 to 9 , where $1=$ poor and $9=$ excellent
In addition to this interaction with time,

1). This relationship also was true when growth of VG178 and SD178 under moderate and severe stress were compared to their growth under no stress. Clipping biomass of VG178 declined more than that of $\mathrm{CC}$ under severe stress.

Recovery of above-ground growth at the end of the four cycles was slow. By 13 days after rewatering the turf, the relative biomass of the moderate stress plots had increased to $72 \%, 80 \%$, and $90 \%$ (relative to the clipping biomass of the nonstressed CC) for CC, SD178, and VG178, respectively. The more retarded turfgrass, which earlier was under severe stress, recovered to $71 \%, 59 \%$, and $53 \%$ for $\mathrm{CC}$, SD178, and VG178, respectively.

Visual ratings. Throughout the selection and drought evaluation process, visual appearance of 'TC178' warranted special attention. As indicated for the severe stress treatment, visual ratings of VG178 or SD178 were higher than for $\mathrm{CC}$ throughout the 2-year test (Fig. 4). Average visual ratings from the end of the four drought cycles (Table 1) show the interaction of drought with visual quality. Under no-stress conditions, CC performed as well as SD178 and VG178, but under moderate and severe drought stress, $\mathrm{CC}$ had a poorer appearance. For SD178 and VG178, visual ratings were $18 \%$ and $28 \%$ greater than $\mathrm{CC}$ for moderate stress and severe stress, respectively. $\mathrm{CC}$ developed dead patches and lost leaves from stolons. SD178 and VG178 wilted with leaves curling, graying, and eventually becoming necrotic at the tips, but neither cultivar developed bare patches or shed leaves.

Visual ratings of SD178 and VG178 showed that they recovered more rapidly than CC. Ten days after watering at the end of the four cycles, visual ratings of the moderately stressed plots had recovered to $86 \%, 90 \%$, and $97 \%$ of the average no-stress plot ratings for CC, SD178, and VG178, respectively. Visual ratings of the severely stressed plots had recovered to $67 \%, 86 \%$, and $73 \%$ of the average nonstressed for CC, SD178, and VG178, respectively.

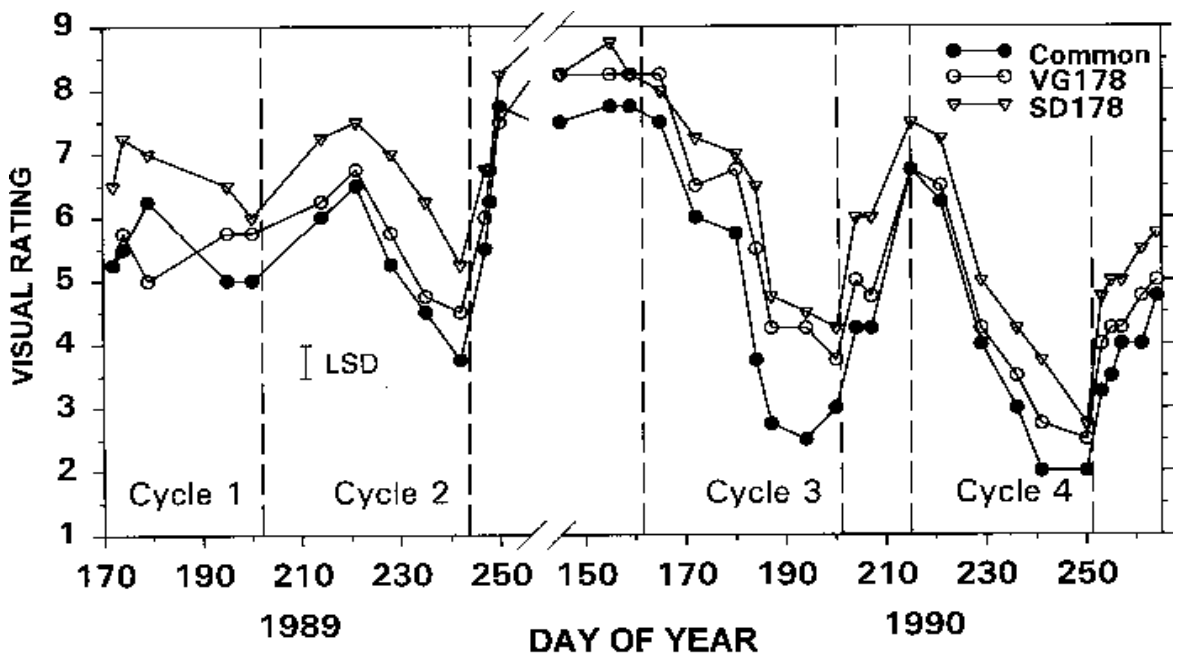

Fig. 4. Visual ratings ( $1=$ dead grass, $9=$ ideal density, color, and uniformity for the species) for common, VG178, and SD178 centipedegrass subjected to the severe stress treatment. Vertical bar is SE of the mean.

\section{Discussion}

Our observations provide evidence that helps describe, in part, the mechanisms of drought resistance in these centipedegrass cultivars. Jones et al. (1981) defined "drought resistance" as the generic term to cover a range of mechanisms whereby plants withstand periods of dry weather. Levitt (1980) defined drought resistance more specifically: for perennials, plants with high drought resistance are those able to survive high levels of stress, either in duration or intensity, by means of drought avoidance, drought tolerance at low leaf water potential, or both.

Drought avoidance may be due to 1) water conservation (lower transpiration, more rapid stomatal closure, fewer stomata, lower cuticular transpiration, decreased rate of water loss, change in leaf angle or reflectance to reduce absorbed radiation), 2) greater water absorption (more effective water uptake and conduction, more extensive root development, more water removed from soil) (Levitt, 1980), or 3) both. Rooting patterns that explore a greater volume of soil or extract a greater quantity of water in a given volume help to maintain water absorption. Also, plants with an extensive vascular system may maintain more water in leaf tissues, when the system is limiting uptake (Jones et al., 1981; Levitt, 1980).

VG178, SD178, and CC absorbed water at about the same rates and withdrew it at the same times from the same portions of the root zone. Although conclusions regarding root density and distribution could not be made directly, root function, as indicated by rates of water extraction from the soil layers, was similar among cultivars. No measurements were made for stomatal closure, absorbed radiation (both indirect measures of water conservation in plants), or transpiration rates (a direct measure of water conservation in plants). The net effect of water conservation by plants, however, is higher amounts of water remaining in the soil profile. There were no significant differences among cultivars for available soil water. Thus, there was no comparative advantage of the new cultivars in drought avoidance.

Drought tolerance at lowered leaf water potential may be achieved by dehydration avoidance or by dehydration tolerance. Dehydration avoidance is accomplished by avoiding growth inhibition or metabolic strain due primarily to osmotic adjustment, stomatal opening at low water potentials, respiration reduction, or uncoupling of transpiration and photosynthesis. Dehydration tolerance is tolerance of turgor loss by protein adaptations or other means or repair of damage on removal of the stress. Drought tolerance merely permits the plant to survive until the water stress is removed (Levitt, 1980).

Although the slightly higher, but not significant, growth of VG178 and SD178 under moderate stress suggests some comparative advantage in dehydration avoidance by these cultivars, their response under severe stress suggests that this avoidance is not an important part of their drought tolerance. Under the 
extended drought periods of the severe stress, clipping biomass of VG178 and SD178 was curtailed more sharply than that of CC, but the former retained stressed and curled leaves and, thus, had a more uniform and greener appearance. Growth of the new cultivars severely decreased under stress. CC leaves continued to dry out, die, and be included in the clipping biomass. Patches of dead grass were found in CC, but not VG178 and SD178 Survival under these severe conditions indicates dehydration tolerance.

Dehydration tolerance also involves ability to regrow after stress is removed. All three cultivars regained clipping biomass at similar rates, but VG178 and SD178 had less damage to repair. Visual appearance of VG178 and SD178, already higher than that of CC, improved rapidly. VG178 and SD178 exhibited superior drought resistance compared to $\mathrm{CC}$. The evidence collected in this study suggests that drought tolerance may be more important than drought avoidance as a mechanism to explain superior, drought-resistance traits.

\section{Literature Cited}

Beard, J.B. 1982. Turf management for golf courses. Burgess, Minneapolis.

Beard, J.B. 1985. Turfgrass culture and water use, p. 45-60. In: V.A. Gibeault and S.T. Cockerham (eds.). Turfgrass water conservation. ANR Publications, Oakland, Calif.

Carrow, R.N. and B.J. Johnson. 1989. Evaluation of slow release nitrogen carriers on centipedegrass. HortScience 24:277-279.

Dickens, R., W.J. Johnston, and R.L. Haaland. 1981. Variability observed in centipedegrass grown from ${ }^{60} \mathrm{Co}$ irradiated seed. Agron. J. 73:674-676.

Hook, J.E. 1985. Irrigated corn management for the coastal plain: Irrigation scheduling and response to soil water and evaporative demand. Georgia Agr. Expt. Sta. Res. Bul. 335.

Hook, J.E., W.W. Hanna, and B.W. Maw. 1992. Quality and growth response of centipedegrass to extended drought. Agron. J. 84:606-612.

Johnson, B.J. 1990. Influence of frequency and dates of plant growth regulator applications to centipedegrass on seedhead formation and turf quality. J. Amer. Soc. Hort. Sci. 115:412-416.

Johnston, W.J. and R. Dickens. 1976. Centipedegrass (Eremochloa ophiuroides) cold tolerance as affected by environmental factors. Agron. J. 68:83-85.

Jones, M.M., N.C. Turner, and C.B. Osmond. 1981. Mechanisms of drought resistance, p. 15-37. In: L.G. Paleg and D. Aspinall (eds.). The physiology and biochemistry of drought resistance in plants. Academic, New York.

Kim, K.S. and J.B. Beard. 1988. Comparative turfgrass evapotranspiration rates and associated plant morphological characteristics. Crop Sci. 28:328-331.

Levitt, J. 1980. Responses of plants to environmental stresses. Vol. II: Water, radiation, salt, and other stresses. 2nd ed. Academic, New York.

Maw, B.W. and J.R. Stansell. 1986. Rainout shelter for tall crop irrigation research. Appl. Eng. Agr. 2:137-140.

SAS Institute. 1982. SAS users guide: Statistics. SAS Institute, Cary, N.C. 